\title{
International Federation for Professionals in Abortion and Contraception (FIAPAC)
}

\author{
Sam Rowlands, ${ }^{1}$ Kristina Gemzell-Danielsson, ${ }^{2}$ Elisabeth Aubény, ${ }^{3}$ Christian Fiala ${ }^{4}$
}

'Honorary Associate Professor, Institute of Clinical Education, Warwick Medical School, University of Warwick,

Coventry, UK

2Professor, Department of

Women's and Children's

Health, Division of Obstetrics

and Gynaecology, Karolinska

Institutet, Stockholm, Sweden

${ }^{3}$ Medical Gynaecologist,

Paris, France

${ }^{4}$ Gynmed Ambulatorium,

Vienna, Austria

\section{Correspondence to}

Dr Sam Rowlands, Institute of

Clinical Education, Warwick

Medical School, Gibbett Hill

Campus, University of Warwick,

Coventry CV4 7AL, UK;

sam.rowlands@warwick.ac.uk

Received 28 July 2011

Accepted 28 July 2011

\section{What is FIAPAC?}

FIAPAC (Fédération Internationale des Associés Professionels de l'Avortement et de la Contraception) is an organisation, founded in 1997 and registered in France. We are now an international organisation, with over 270 members around the world. Our members come from a wide range of disciplines working in abortion care: counsellors, administrators, nurses, doctors, policymakers, researchers, women's groups, global leaders in reproductive health, lawyers and ethicists.

\section{How did you start?}

When the European Society of Contraception (ESC) was founded in 1988, its main emphasis was on contraception (now, as the European Society of Contraception and Reproductive Health, it does, however, have a somewhat broader remit). Consequently, those professionals working primarily in abortion care did not have their own forum. At a conference entitled 'Abortion Matters', held in Amsterdam in 1996, the need for such a forum was highlighted and it was resolved to form a new organisation - FIAPAC. The founding organisations were ANCIC (French), Beauhuis \& Bloemenhoveklineik (Dutch), LUNA (Belgian), GACHEPA (Belgian) and Stimezo (Dutch). FIAPAC's first President was Dr Elisabeth Aubény, an internationally renowned Paris-based gynaecologist, well known for her work on mifepristone.

\section{How does FIAPAC work now?}

From 2002 to 2008, under the presidency of Dr Christian Fiala, FIAPAC experienced a significant transformation from a regional French-speaking initiative into a truly international organisation. Although the majority of our membership comes still from within Europe, we have members from around the world. Our Board is elected from member countries; each country that has five or more members has representation on the Board. The current FIAPAC President is Professor Kristina Gemzell-Danielsson of the World
Health Organization Collaborating Centre, Karolinska Institutet, in Stockholm.

\section{How are you organised and funded?}

To date the organisation has been run without any paid staff. All work has been on a voluntary basis. Work is mainly done by the Board of Directors and the Executive Committee; and also by the Scientific Committee appointed for each Congress. When each Congress is run there is a Local Organising Committee made up mainly of active members and colleagues in the host country.

Unlike other specialties in medicine, sponsorship is hard to come by. The pharmaceutical industry is generally nervous about being associated with abortion, despite the fact that they hold the only solution to reducing the frequency of abortion: improving use of reliable contraception.

\section{What do you currently do?}

The main activity of the organisation has been running a Congress every 2 years. Over the years these have increased in size, from 35 participants representing three countries in 1997 to 601 participants representing 53 countries at the IXth Congress in 2010. The most recent Congresses have been held in Rome, Vienna, Berlin and Seville. The Congresses comprise highquality presentations and debate; but possibly more important to members is the chance to network with colleagues.

In addition to the Congresses, a FIAPAC seminar was held in Moscow in 2005 at the invitation of FIAPAC members in Russia. FIAPAC has also been invited to participate with special sessions at ESC meetings during the last few years and invited to many conferences such as the National Abortion Federation in the USA and to advise when medical abortion is introduced into new countries.

Why do your members join FIAPAC? Those working in abortion care generally feel isolated. This is because abortion care still carries a stigma among the medical 
and nursing professions. In many countries there are legal or administrative restrictions that make abortion in certain circumstances of uncertain legality. All this is against the backdrop of induced abortion remaining a criminal offence in most countries, unless certain requirements are fulfilled. Our North American and Australian colleagues work in an environment in which religious anti-abortion feeling has run so high that several individuals working in the field have been murdered. This then opens up another unique difficulty for members, namely that they risk their own lives and those of their families and work colleagues.

Many professionals who never have contact with women requesting abortion find it hard to appreciate how abortion care is a specialty in its own right with its own scientific literature, professional guidance and clinical standards. Members feel passionately about their work and take great pride in it, but cannot easily discuss their concerns, ideas and problems in a more general professional arena. Abstracts put forward for presentation are less likely to be selected at general meetings because the area of work is not considered so legitimate as, say, assisted conception.

For all these reasons, professionals join FIAPAC and find attending FIAPAC Congresses so stimulating and rewarding. They have a forum where they can openly discuss varied administrative, social, medical, legal and political issues with like-minded colleagues.

\section{What does the future hold?}

Recently, FIAPAC has been developing a number of initiatives. One is an exchange programme whereby members can visit centres of excellence in abortion care. Another is a system of bursaries for young members to enable them to travel to see abortion in other settings. Our website (www.fiapac.org) has also been recently redesigned.

We are also looking to further improve the quality of FIAPAC Congresses by using professional conference management services to remove the burden from those currently volunteering for this work. The Board is determined, however, despite increasing automation and efficiency, that FIAPAC will retain its unique family feeling and big heart.

Our next Congress will be the first held in the UK and will be in Edinburgh on 19-20 October 2012. Members from the UK look forward to welcoming professionals from around the world to a special Scottish experience. Further details are available by contacting FIAPAC direct (see Further Information).

\section{Competing interests None}

Provenance and peer review Commissioned; internally peer reviewed.

\section{Editor's note}

This article is one in a series of occasional articles on key health organisations worldwide. The Journal would be pleased to hear from other organisations, particularly those based outside the UK, which would like to be similarly profiled.

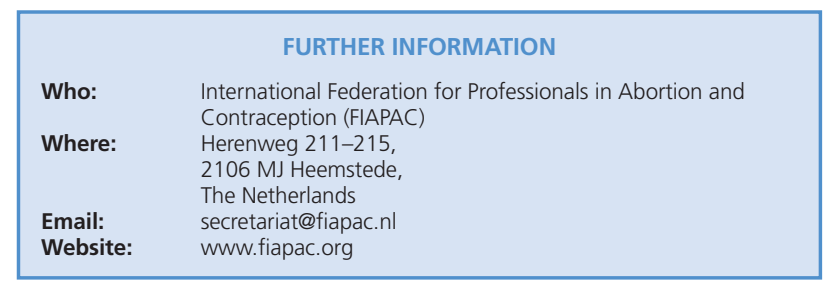

